\title{
The serendipity alpha gene encodes a membrane-associated protein required for the cellularization of the Drosophila embryo
}

\author{
François Schweisguth, ${ }^{1,3}$ Jean-Antoine Lepesant, ${ }^{1}$ and Alain Vincent ${ }^{2}$ \\ IInstitut Jacques Monod, Centre National de la Recherche Scientifique et Université Paris 7, 75251 Paris Cedex 05, France; \\ ${ }^{2}$ Centre de Recherches de Biochimie et Génétique Cellulaires du Centre National de la Recherche Scientifique, 31062 \\ Toulouse Cedex, France
}

The Drosophila serendipity alpha (sry a) gene is specifically transcribed at the blastoderm stage, from nuclear cycle 11 to the onset of gastrulation, in all somatic nuclei. This pattern of transcription and a zygotic cellularization defect observed in embryos homozygous for $D f(3 R) X 3 F$, a deficiency covering the sry locus, suggest that sry $\alpha$ plays a role in the cellularization of the syncytial blastoderm embryo. P-element rescue experiments show that one copy of the sry a gene rescues the defective cellularization phenotype associated with $D f(3 R) X 3 F$. Lack of sry a activity results in erratic disruptions of the cytoskeleton at the beginning of the interphase of mitotic cycle 14. Multinucleate cells form during plasma membrane invagination.

Immunodetection of the sry $\alpha$ protein using anti-sry $\alpha$ polyclonal antibodies indicates that the $58 \cdot \mathrm{kD}$ sry $\alpha$ protein accumulates transiently at the blastoderm stage. The sry $\alpha$ protein is associated with the invaginating plasma membrane and colocalizes with F-actin. We propose that sry $\alpha$ is involved in the localization of membrane furrows within the syncytial blastoderm.

[Key Words: serendipity; cellularization; F-actin; blastoderm; Drosophila]

Received December 29, 1989; revised version accepted March 1, 1990.

The powerful molecular genetics of Drosophila make its embryo an attractive model for the identification of the various cytoskeletal components involved in cellular blastoderm formation. Despite increasing knowledge of the genetic control of Drosophila embryogenesis (Ingham 1988), little is known about the initiators and mechanistic effectors of the synchronous cellularization of the somatic nuclei at the blastoderm stage.

Following fertilization, the zygotic nuclei divide 13 times without cytokinesis to form the syncytial blastoderm embryo (Foe and Alberts 1983). Most of the nuclei, initially centrally located, migrate stepwise to the cortical cytoplasm during cycles $7-10$. The first cells to be formed are the pole cells, precursor of the germ line cells. Polar buds form during cycle 9 and pinch off at the end of mitotic cycle 10 ( $1 \mathrm{hr}$ and $20 \mathrm{~min}$ after fertilization). Three additional division cycles (nuclear cycles 11-13) take place at the cortex. All 6000 somatic nuclei, which form a uniform monolayer, are then synchronously cellularized during the interphase of cycle $14 / 2 \mathrm{hr}$ to $2 \mathrm{hr}$ and $50 \mathrm{~min}$ ). Cellularization is preceded by an increase in plasma membrane surface with the forma-

${ }^{3}$ Corresponding author. tion of multiple villous projections (Fullilove and Jacobson 1971). The cellularization process may be separated into two phases based on the cellularization rate: an initial "slow phase" (35 min) followed by a "fast phase" (20 min). These differences in the rate of membrane invagination presumably reflect different mechanisms of furrow formation (Merrill et al. 1988), such as the unwinding of the membrane accumulated in villous projections (Fullilove and Jacobson 1971), which results in the flattening of the egg surface, or as the lateral fusion of newly synthesized endomembranes (Sanders 1975; Turner and Mahowald 1976). The invagination of the plasma membrane between adjacent nuclei is accompanied by a reorganization of the cytoskeleton (Warn et al. 1980; Warn and Magrath 1983; Warn and Warn 1986; Pesacreta et al. 1989). During the slow phase, F-actin, which accumulates in the cortex, is associated with the newly formed furrows. Although the cortical actin meshwork progressively disappears during the fast phase, the actin filaments (F-actin) are found along the furrow membrane and associated at the base of the furrow with myosin (Warn and Warn 1986), forming a ring-like structure, or contractile ring, enveloping the furrow canal. The furrow canal is defined as the widening of the intercellular space between the apposed 
membranes that surround each nucleus at the level of the cellularization front (Fullilove and Jacobson 1971).

The genetic basis of cellularization is still poorly documented. Female sterile mutations have been isolated that block development of the embryo at cellularization (Rice and Garen 1975; Zalokar et al. 1975; Schüpbach and Wieschaus 1989|, indicating that some gene products involved in this process are deposited in the egg during oogenesis. For example, cytoskeletal proteins such as actin, myosin, tubulin and spectrin, are already accumulated in the unfertilized egg (Karr and Alberts 1986; Warn 1986; Pesacreta et al . 1989). In addition to the maternal contribution, at least eight loci are zygotically required for the formation of the cellular blastoderm embryo (Merrill et al. 1988; Wieschaus and Sweeton 1988). Among these, one locus defined by the deficiency $D f(3 R) X 3 F$ (99D1-2; 99E1) (K. Kongsuwan, J. Merriam, and J.A. Lengyel, pers. comm.) is required for the regular spacing of the invaginating membrane around each nucleus (Merrill et al. 1988). The deletion of this chromosomal region leads to the formation of cells that may contain multiple nuclei.

The $D f(3 R) X 3 F$ deficiency encompasses the blastoderm-specific serendipity alpha (sry $\alpha$ ) gene (99D 4-8) (Vincent et al. 1985). sry $\alpha$ transcription is first detected by in situ hybridization at the syncytial blastoderm stage (nuclear cycle 11), peaks during cellularization, and is no longer detectable during germ-band extension (Schweisguth et al. 1989). In spite of a detailed molecular characterization of the sry $\alpha$ gene (Vincent et al. 1985), the function of the sry $\alpha$ protein has remained elusive. We show here that the cellularization defects observed in $D f(3 R) X 3 F$ homozygous embryos are due to the lack of the sry $\alpha$ gene. Data are presented on the spatio-temporal distribution and subcellular localization of the sry $\alpha$ protein, which suggest that it is involved in the localization of the actin filaments just prior to and during plasma membrane invagination.

\section{Results}

\section{Cellularization defects of Df(3R)X3F homozygous embryos}

Here, we extend the original description given by Merrill et al. (1988) of $D f(3 R) X 3 F$ homozygous embryos at the blastoderm stage. Embryos were examined with DAPI, (4,6 diamidino-2-phenylindole), which reveals nuclei, and with fluorescently labeled phalloidin, which specifically interacts with F-actin (Warn and Magrath 1983). No zygotic defects could be observed during the first 13 cleavage divisions, except for occasional irregularities in nuclei migration and distribution. These were shown to be due to a dominant maternal effect (data not shown), possibly resulting from aneuploidy, as has been documented in other cases (Garcia-Bellido et al. 1983). During interphase of cycle 14, local disruptions in the hexagonal array of F-actin are detectable (Fig. 1B). Such defects were observed in one-quarter of the progeny (see Table 1) as expected for a fully penetrant zygotic phenotype. The cellularization process is not arrested, but the plasma membrane invaginates irregularly around clustered nuclei (Fig. 1D), enclosing multiple nuclei, from 1 to $\sim 25$, into single cells. However, the initiation and rate of plasma membrane invagination, as well as nuclear elongation and nuclei position relative to the surface, appear normal. These irregularities in the cytoskeleton array are extended over the whole surface of the egg, the greatest disruptions predominantly occurring at both poles (Fig. 1B). Despite these defects, cellularization and F-actin distribution appear normal in regions where mononucleate cells are formed. In particular, the baso-apical distribution of F-actin at the cortex and along the furrows is essentially similar to that observed in wild-type embryos (Fig. 1E,F).

F-actin is not the only cytoskeleton component whose distribution is abnormal in embryos homozygous for $D f(3 R) X 3 F$. Spectrin, a major component of the meshwork associated with the inner face of the plasma membrane (Pesacreta et al. 1989), is distributed in a manner strictly similar to F-actin both in wild-type and $D f(3 R) X 3 F$ blastoderm-stage embryos (Fig. 2). In these surface views, F-actin and spectrin appear concentrated around normal or multinucleate cells, because of the deep cleavage furrows. Anti- $\alpha$-spectrin antibodies la kind gift from Dr. Branton) thereby provide an alternative probe to phalloidin. As phalloidin binding is lost following the methanol fixation procedure commonly used in immunofluorescence, and as the methanol fixation procedure allows processing of a larger number of embryos compared to devitellinization through hand peeling, anti- $\alpha$-spectrin antibodies were subsequently used in the double fluorescence-labeling experiments. Microtubule distribution was analyzed by using an anti$\alpha$-tubulin monoclonal antibody in embryos homozygous for $D f(3 R) X 3 F$, identified as such by the disruptions in the spectrin pattern. At mid-cellularization, both axial and cortical microtubules are partly organized following cell limits corresponding to the multinucleate cells, although cortical microtubules are still detectable between clustered nuclei (data not shown). However, although an irregular pattern of spectrin may already be observed at the time of furrow positioning (Fig. 3C), the tubulin network still appears normal at that stage (Fig. $3 \mathrm{D}$ ). Centrosome splitting is also normal (data not shown).

Phenotypic rescue of Df(3R)X3F homozygous embryos with an additional copy of sry $\alpha$

The $D f(3 R) X 3 F$ deficiency spans the genomic region 99 D1-2; $99 \mathrm{El}$ (K. Kongsuwan, J. Merriam, and J.A. Lengyel, pers. comm.). It uncovers several transcription units, among which the rp49, the sry, and Janus (Jan) genes have been extensively characterized (Kongsuwan et al. 1985; Vincent et al. 1985; Yanicostas et al. 1989). These transcription units contribute to the complex em- 

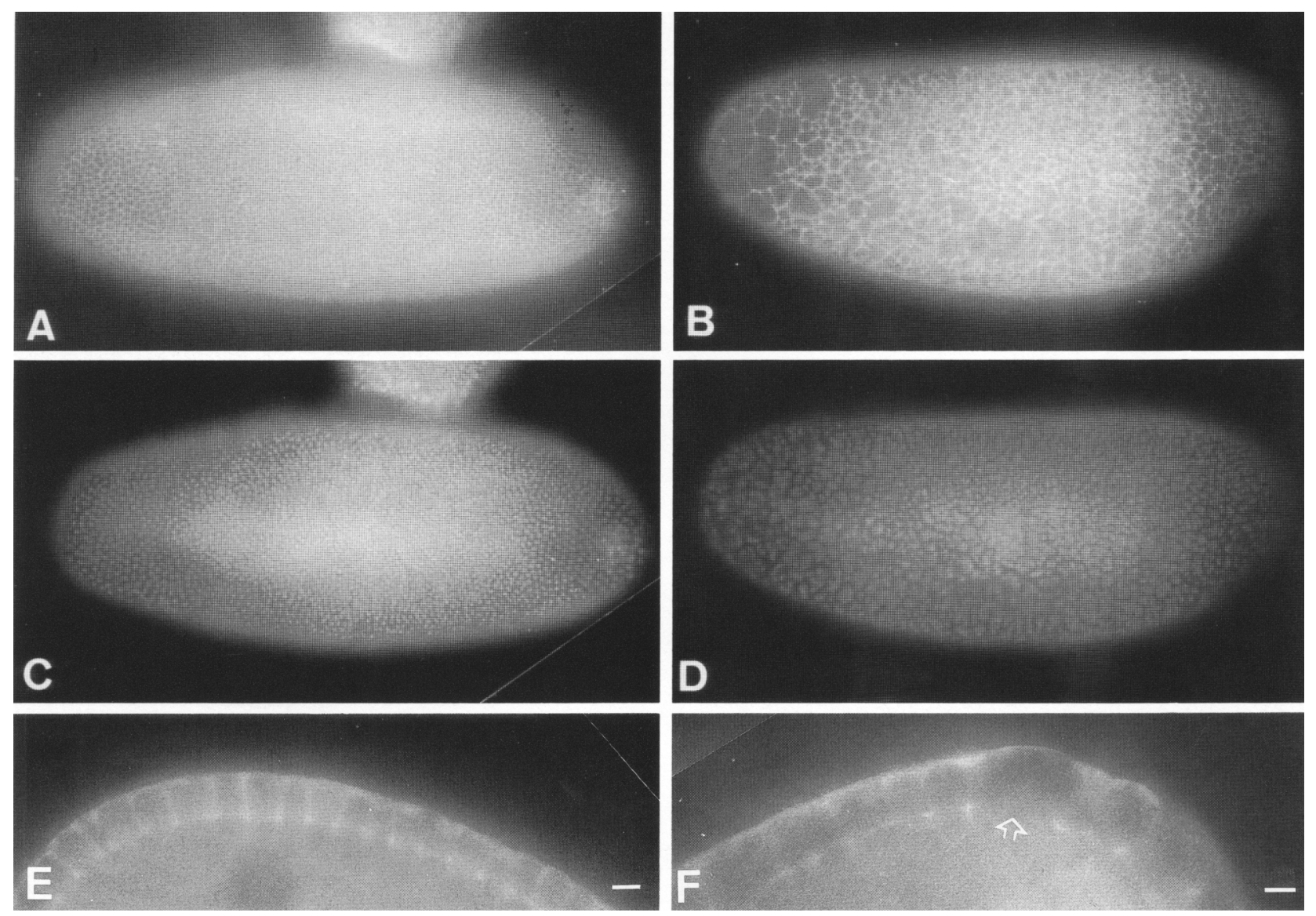

Figure 1. Disruption of the F-actin array in cycle 14 embryos homozygous for $D f(3 R) X 3 F$. The distribution of $F$-actin $(A, B, E$, and $F)$ and nuclei $(C$ and $D)$ is visualized on whole embryos using fluorescently labeled phalloidin and DAPI. A wild-type embryo at the interphase of cycle 14 is shown as a control $\mid A, C$, and $E \mid$. Note the irregular actin arrays $(B$ and $F)$ and abnormal clustering of nuclei $(D)$ in the $D f(3 R) X 3 F$ embryo at the cellular blastoderm stage; the most extensive disruptions in the F-actin array are observed at both poles. Embryos were maintained at $22^{\circ} \mathrm{C}$. Embryos, $\sim 450 \mu$ in length, are oriented with the anterior pole to left. Bar, $5 \mu$ (in $E$ and $F$ ).

bryonic lethal phenotype exhibited by $D f(3 R) X 3 F$ homozygous embryos. However, because the zygotic cellularization phenotype can be detected very early, at the onset of zygotic transcription, it very likely results from the nonexpression of a strictly zygotic gene at the blastoderm stage. We therefore hypothesized that the cellularization phenotype of $D f(3 R) X 3 F$ homozygous embryos could result from the lack of the blastoderm-specific sry $\alpha$ gene product. This hypothesis was tested using P-element-mediated germ line transformation with constructs (Table 1) containing either the sry $\alpha$ gene alone $\left(\mathrm{P}\left[\right.\right.$ sry $\left.\left.\alpha, \mathrm{ry}^{+}\right]\right)$, or the entire Jan and sry loci (P[Jan/sry, ry $\left.^{+}\right]$. Chromosomes carrying a $\mathrm{P}\left[\right.$ sry $\left.\alpha, \mathrm{ry}^{+}\right]$or a $\mathrm{P}[\mathrm{Jan} /$ sry, $\left.\mathrm{ry}^{+}\right]$were then crossed in the $D f(3 R) X 3 F$ line and tested for their ability to suppress the cellularization phenotype, as visualized at the interphase of cycle 14 by using DAPI and phalloidin. The results, shown in Table 1 , indicate that the cellularization phenotype associated with $D f(3 R) X 3 F$ is fully rescued in both lines, that is, the hexagonal actin array is no longer disrupted and all nuclei are regularly spaced and individually cellularized. A single copy of the sry $\alpha$ gene is thus sufficient to rescue the cellularization defect seen in $D f(3 R) X 3 F$ embryos.

\section{Immunodetection of the $58-\mathrm{k} D$ sry $\alpha$ protein}

Polyclonal antibodies specific to the sry $\alpha$ protein were prepared to follow the expression and localization of the sry $\alpha$ protein during cellularization. Sera were raised in rabbits against sry $\alpha$ polypeptides produced in Escherichia coli. Immunoblotting analysis of embryonic extracts with affinity-purified anti-sry $\alpha$ antibodies specifically revealed a $58-\mathrm{kD}$ protein (Fig. 4, lanes $\mathrm{b}$ and $\mathrm{c}$ ). This band is specific of blastoderm-stage embryos $(2-4 \mathrm{hr})$. When one precisely staged individual embryo of the $D f(3 R) X 3 F$ stock is loaded in each slot, this band is detectable in some lanes but not in others, suggesting that this protein is absent in $D f(3 R) X 3 F$ homozygous embryos (data not shown). This protein comigrates with the in vitro translation product of sry $\alpha$ synthetic RNA (Fig. 4, lane a). Its size, $58 \mathrm{kD}$, as measured by SDS-PAGE, is close to that predicted from the nucleic acid sequence of the gene $(59 \mathrm{kD})$. We conclude that this $58-\mathrm{kD}$ protein is the sry $\alpha$ protein. Following fractionation of an embryonic extract by centrifugation, the sry $\alpha$ protein is found in both cytosolic and crude membrane fractions (Fig. 4, lanes $b$ and $c$. 
Table 1. Rescue of the cellularization defect associated with the Df(3R)X3F deficiency by one copy of the sry a gene

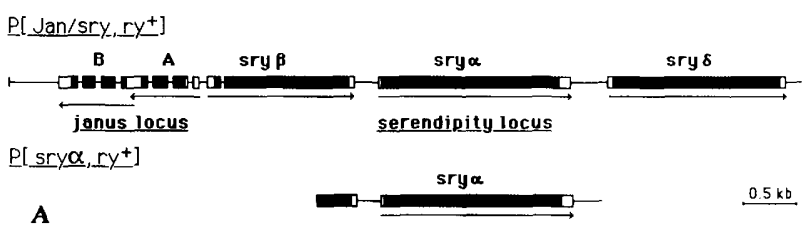

B

\begin{tabular}{|c|c|c|}
\hline line & genotype & $\begin{array}{l}\text { cellularizetion defects } \\
\text { at cycle } 14\end{array}$ \\
\hline$D f(3 R) \times 3 F$ & $\pm \frac{\mathrm{Df}(3 \mathrm{R}) \times 3 \mathrm{P}}{\mathrm{TM} 3}$ & $14 / 56$ \\
\hline s2 & 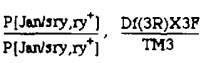 & 0133 \\
\hline sal & $\frac{\mathrm{P}\left[\operatorname{sry} \alpha, r y^{+}\right]}{\mathrm{P}\left[\operatorname{sr} \alpha, r \mathrm{r}^{+}\right]}, \frac{\mathrm{Df}(3 \mathrm{R}) \mathrm{X} 3 \mathrm{~F}}{\mathrm{TM} 3}$ & 0152 \\
\hline
\end{tabular}

(A) Genomic and transcriptional organization of the lan/sry locus regions (Vincent et al. 1985; Yanicostas et al. 1989) included in the $\mathrm{P}$ elements $\mathrm{P}\left[\mathrm{Jan} / \mathrm{sry}, r \mathrm{r}^{+}\right]$and $\mathrm{P}\left[\right.$ sry $\left.\alpha, r \mathrm{y}^{+}\right]$. Intergenic regions are represented as a single line, coding sequences are boxed, and open reading frames are blackened. Transcripts are drawn as arrows, indicating the direction of transcription. Bar, $0.5 \mathrm{~kb} .(B)$ The genotypes of lines listed in the left column are given in the central column. The $D f(3 R) X 3 F$ stock is indicated on the first line as a control experiment. Note that the $D f(3 R) X 3 F$ chromosome also carries a $\mathrm{P}\left[r p 49, r y^{+}\right]$element at $84 \mathrm{~F}$ on the cytological map (Kongsuwan et al. 1985). Phenotype refers to the hexagonal $F$-actin distribution around each nucleus in cellular blastoderm embryos (interphase of cycle 14). The number of embryos showing cellularization defects is given with reference to the total number of embryos examined. In the $D f(3 R \mid X 3 F$ stock only, one-quarter of the progeny, corresponding to the $D f(3 R) X 3 F$ homozygous embryos, show cellularization defects.

\section{Expression of the sry $\alpha$ protein during early} embryogenesis

The sry $\alpha$ protein was detected by indirect immunostaining on whole-mount embryos. The absence of staining over one-quarter of the progeny of $D f(3 R) X 3 F$ heterozygous parents (Fig. 5G,H) confirms the specificity of our sera.

In wild-type embryos no signal is detectable before cycle 12 (Fig. 5A). Very weak staining is observed at nuclear cycle 12 and 13 (Fig. 5B). The signal intensity increases sharply during the interphase of mitotic cycle 14 (Fig. 5C,D). The staining is evenly distributed, along both axes, over the entire surface of the embryos, and is also detectable around yolk nuclei, whereas pole cells are not stained. The signal disappears rapidly as gastrulation proceeds (Fig. 5E,F).

The sry $\alpha$ protein is associated with the invaginating membrane

The subcellular localization of the sry $\alpha$ protein was examined by indirect immunofluorescence on cryostat sections throughout cellularization (Fig. 6). No immuno- fluorescence signal was observed in syncytial blastoderm embryos before cycle 13. A faint signal could then be seen in the cap region (Fig. 6A). At the beginning of the interphase of mitotic cycle 14 , the sry $\alpha$ protein accumulates close to the folds and microprojections of the plasma membrane (Fig. 6B). During both the slow (Fig. 6C) and fast (Fig. 6D) phases of cellularization, the sry $\alpha$ protein is associated with the invaginating plasma membrane. Fluorescent dots are detectable at the cellularization front, at the level of the furrow canals (Fig. $6 \mathrm{C})$. The localization of the sry $\alpha$ protein, associated with the membrane in the cortex and along the furrow, and differentially accumulated at the cellularization front, is similar to that of F-actin (cf. Figs. 1E and 6C). A weaker signal is also detectable in the cytoplasm during cellularization (Fig. 6C-E). In contrast, the signal becomes essentially cytoplasmic at the end of cellularization (Fig. 6E) and is also detected beneath the cell bases (Fig. 6E); then it fades away during gastrulation.

\section{Discussion}

Hypotheses concerning the molecular role of the sry $\alpha$ protein stem from an analysis of the early phenotype of $D f(3 R) X 3 F$ homozygous embryos, from its rescue by a transposed sry $\alpha$ gene, and from the subcellular immunolocalization of the sry $\alpha$ protein. The phenotype associated with $D f(3 R) X 3 F$ may be considered as a null phenotype, because it corresponds to a complete lack of function. At the blastoderm stage, embryos homozygous for this deficiency display disnuptions of the hexagonal

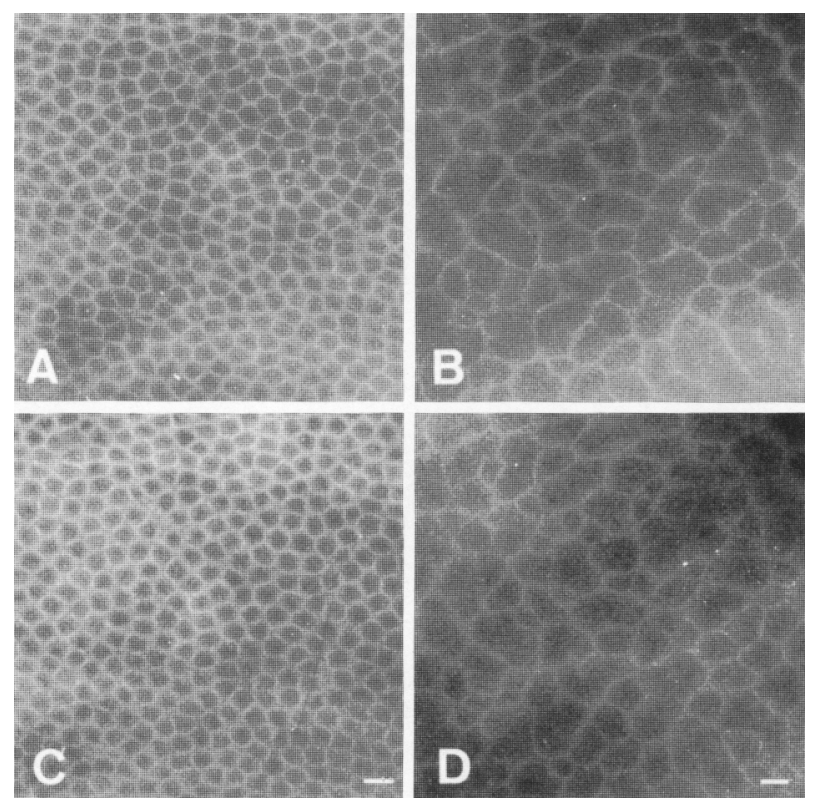

Figure 2. Spectrin as a marker of the F-actin meshwork. Factin $(A$ and $B)$ and spectrin $\mid C$ and $D)$ localization are shown in surface views in wild-type $(A$ and $C)$ and $D f(3 R) X 3 F$ embryos $(B$ and $D \mid$. The focal plane is just above the cellularization front. Embryos were maintained at $29^{\circ} \mathrm{C}$, with increased temperature resulting in a more severe phenotype; almost no single mononucleate cells are observed under these conditions. Bar, $5 \mu$. 

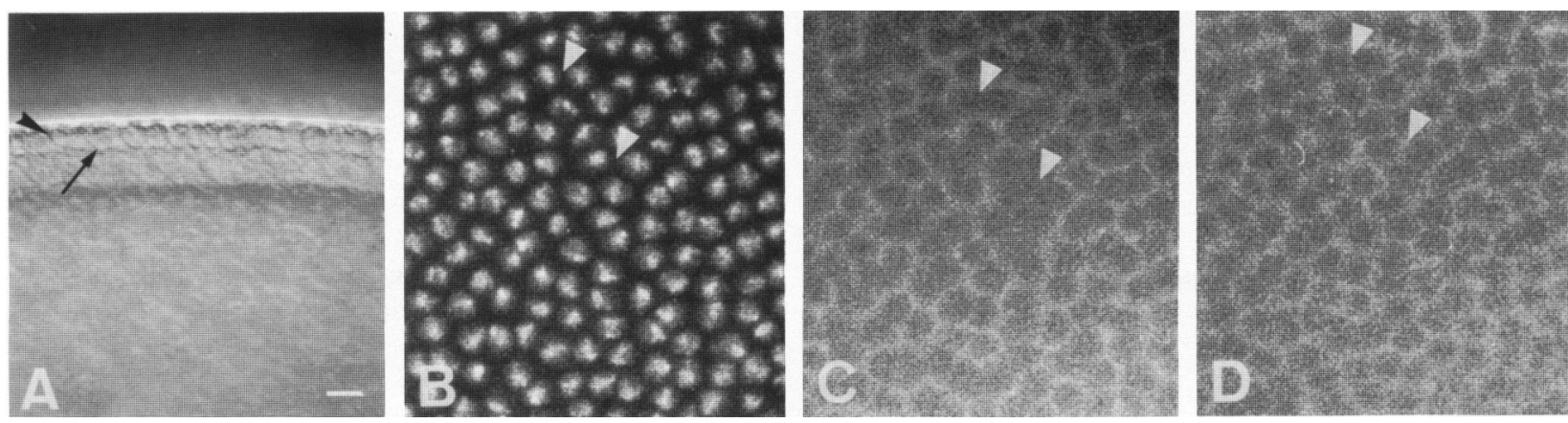

Figure 3. Initial cellularization defects in an early cycle $14 D f(3 R) X 3 F$ embryo. A double immunofluorescence-labeling experiment reveals the nuclei $(B)$, spectrin $(C)$, and tubulin $(D)$ distribution. The white arrowheads indicate cytoplasmic internuclear spaces where tubulin is detectable $(D)$ and where spectrin is absent $(C)$. The precise developmental stage of the embryo is determined according to nuclei elongation (black arrow) and to membrane invagination (black arrowhead), which is visible in a transverse view of the same embryo, using Nomarski optics $(A)$. Embryos were maintained at $22^{\circ} \mathrm{C}$ in this experiment. Bar, $15 \mu(A) ; 5 \mu(B-D)$.

F-actin array. This phenotype is fully rescued by a single copy of the sry $\alpha$ gene. However, the embryonic lethality associated with the deficiency was not rescued in these P-element rescue experiments, indicating that embryonic lethal genes other than the sry and Jan genes map within the boundaries of the deficiency breakpoints $(99$ D1 2 ; 99 E1). Whether the sole lack of sry $\alpha$ activity may lead to the death of the embryo is still an open question in the absence of a sry $\alpha$ null mutation. These

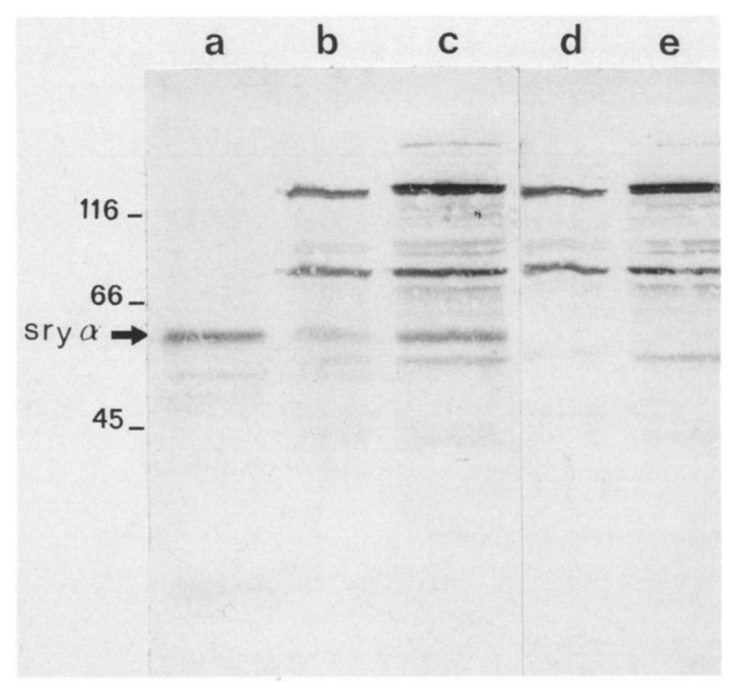

Figure 4. Western blot analysis of the sry $\alpha$ protein. In vitrotranslation products of the synthetic sry $\alpha$ RNA in a rabbit reticulocyte lysate (lane $a$ ) and embryonic extracts of blastodermstage embryos (lanes $b-e$ ) were separated by SDS-PAGE. Ten micrograms of protein was loaded per slot. The $58-\mathrm{kD}$ sry $\alpha$ protein is specifically detected by the affinity-purified anti-sry $\alpha$ antibodies in the cytosolic $(b)$ and crude membrane $(c)$ fractions. The other visible bands are due to nonspecific binding of the secondary antibody, as revealed by incubating the same extracts with the secondary antibody alone (lanes $d$ and $e$ ). Nonspecific binding to the $130-\mathrm{kD}$ doublet and the $80-\mathrm{kD}$ proteins has been reported previously (Driever and Nüsslein-Volhard 1988; Piovant and Lena 1988). Molecular weight markers (in $\mathrm{kD}$ ) are indicated at left.
P-element rescue experiments also provide a functional definition of the sry $\alpha$ gene that is consistent with our previous mapping analysis of the cis-acting regulatory elements of the sry $\alpha$ gene (Vincent et al. 1986; Schweisguth et al. 1989).

The sry $\alpha$ protein is mostly localized along apical and furrow membranes and accumulates at the level of the furrow canal. Although membrane associated, the sry $\alpha$ protein is probably not an integral membrane protein. First, the sry $\alpha$ protein is also detected in the cytoplasm on cryostat sections. Second, it is present in both the crude membrane and cytosolic fractions, and when the crude membrane fraction is submitted to Triton X-114 phase separation (Bordier 1981), the sry $\alpha$ protein is recovered in the aqueous phase (data not shown). Finally, there are no putative membrane-spanning domains nor signal sequence in the sry $\alpha$ protein sequence (Vincent et al. 1985). The localization of the sry $\alpha$ protein to the inner face of the membrane may be mediated by protein interactions.

The accumulation of the sry $\alpha$ protein along the furrow and close to the furrow canal is reminiscent of the localization of the actin filaments (Warn and Magrath 1983), myosin (Warn et al. 1980), and particular actin-binding proteins (Miller et al. 1989). The distribution of the sry $\alpha$ protein differs from those of spectrin, which is not detectable at the furrow canal (Pesacreta et al. 1989), and tubulin (Warn and Warn 1986).

The colocalization of the sry $\alpha$ protein and F-actin raises the hypothesis that sry $\alpha$ could be an actinbinding protein required for the initial positioning and/or the stability of the F-actin network. The essential role of the F-actin in the inward extension of the growing plasma membrane and the distribution of the nuclei in an even cortical monolayer was demonstrated by the injection in early cycle 14 embryos of cytochalasin B, an inhibitor of actin polymerization (Foe and Alberts 1983; Edgar et al. 1987). Noticeably, the number and size of multinucleate cells do not increase between mid-cellularization and the end of cellularization in embryos homozygous for $D f(3 R) X 3 F$ (data not shown). As disruptions do not progressively arise throughout cellu- 
Role of sry $\alpha$ in the blastoderm cellularization

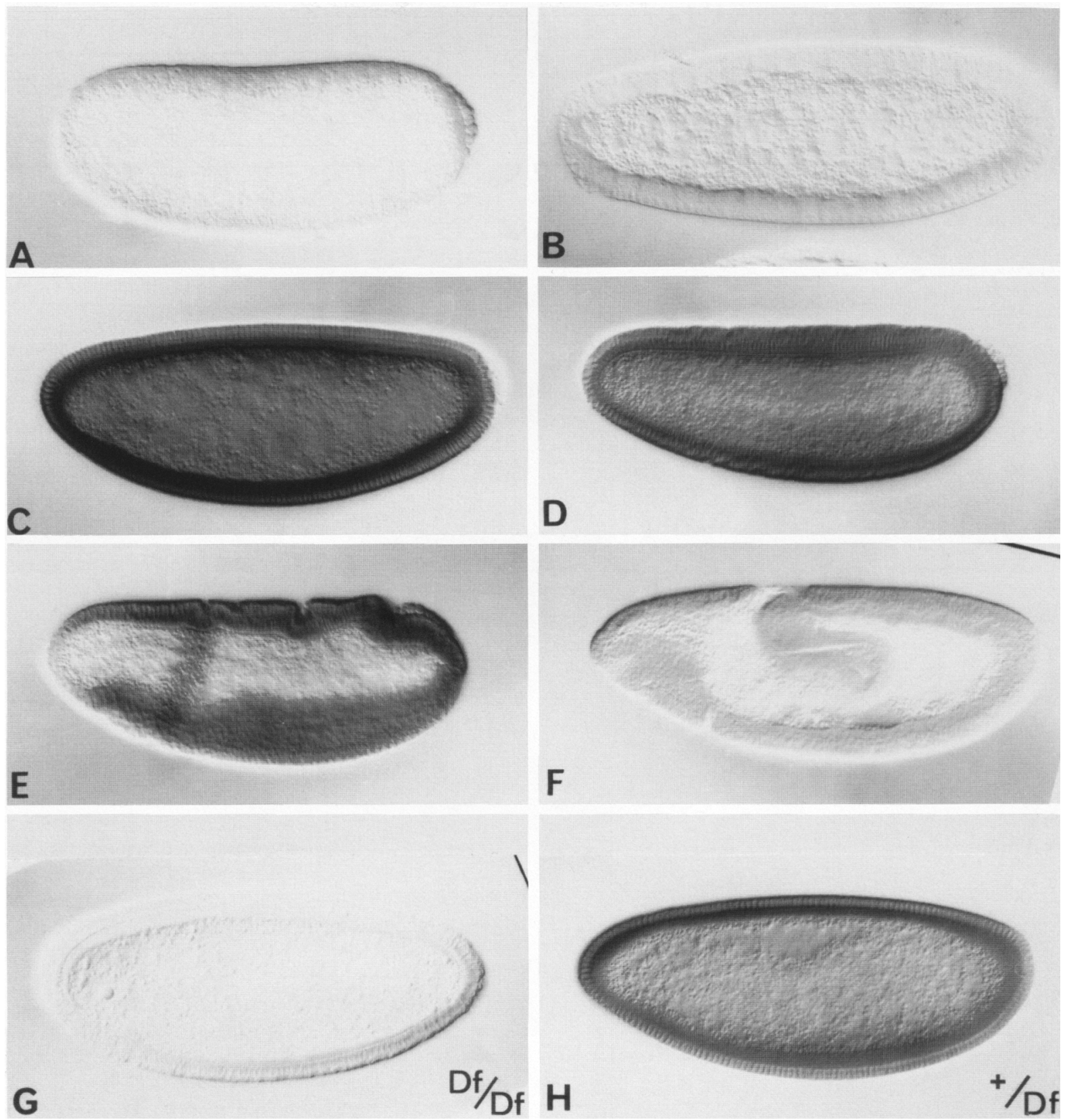

Figure 5. Pattern of accumulation of the sry $\alpha$ protein in whole-mount embryos. Wild-type embryos at different stages were stained for the sry $\alpha$ protein. (A) Pole-cell formation (nuclear cycle 10; stage 3). (B) Syncytial blastoderm (nuclear cycle 12; stage 4). At this stage, the signal is too weak to be visualized with Nomarski optics. $(C)$ Cellular blastoderm (mid-interphase cycle 14; stage 5). Note the absence of staining over pole cells. $(D)$ Early gastrulation (stage 6). (E) Gastrulation (transition from stage 6 to 7$)$. (F) Germ-band extension (late stage 8 ). Immunostaining specificity is given by comparing, in the same batch, the staining of embryos homozygous for $D f(3 R) X 3 F(G$; stage 4$)$ with heterozygous embryos $(H$; stage 4$)$. In all cases, anterior is at left, dorsal at top. Staging is according to Campos-Ortega and Hartenstein (1985).

larization, the sry $\alpha$ protein is probably not required for the stabilization of the filaments of actin along the furrow during membrane invagination. The initial abnormal positioning of F-actin in embryos homozygous for $D f(3 R) X 3 F$ suggests that the sry $\alpha$ protein participates in cell demarcation either by properly positioning the F-actin array at the beginning of cycle 14 or by stabilizing the newly formed furrows.
A number of actin-binding proteins have now been sequenced (for review, see Tellam et al. 1989). The absence of sequence similarity between the sry $\alpha$ protein and previously identified actin-binding proteins raises the possibility that proteins specifically involved in reorganizing the cytoskeleton at unique developmental stages have yet to be identified. Indeed, $\sim 40$ actin-binding proteins have been isolated from the Drosophila embryo by 

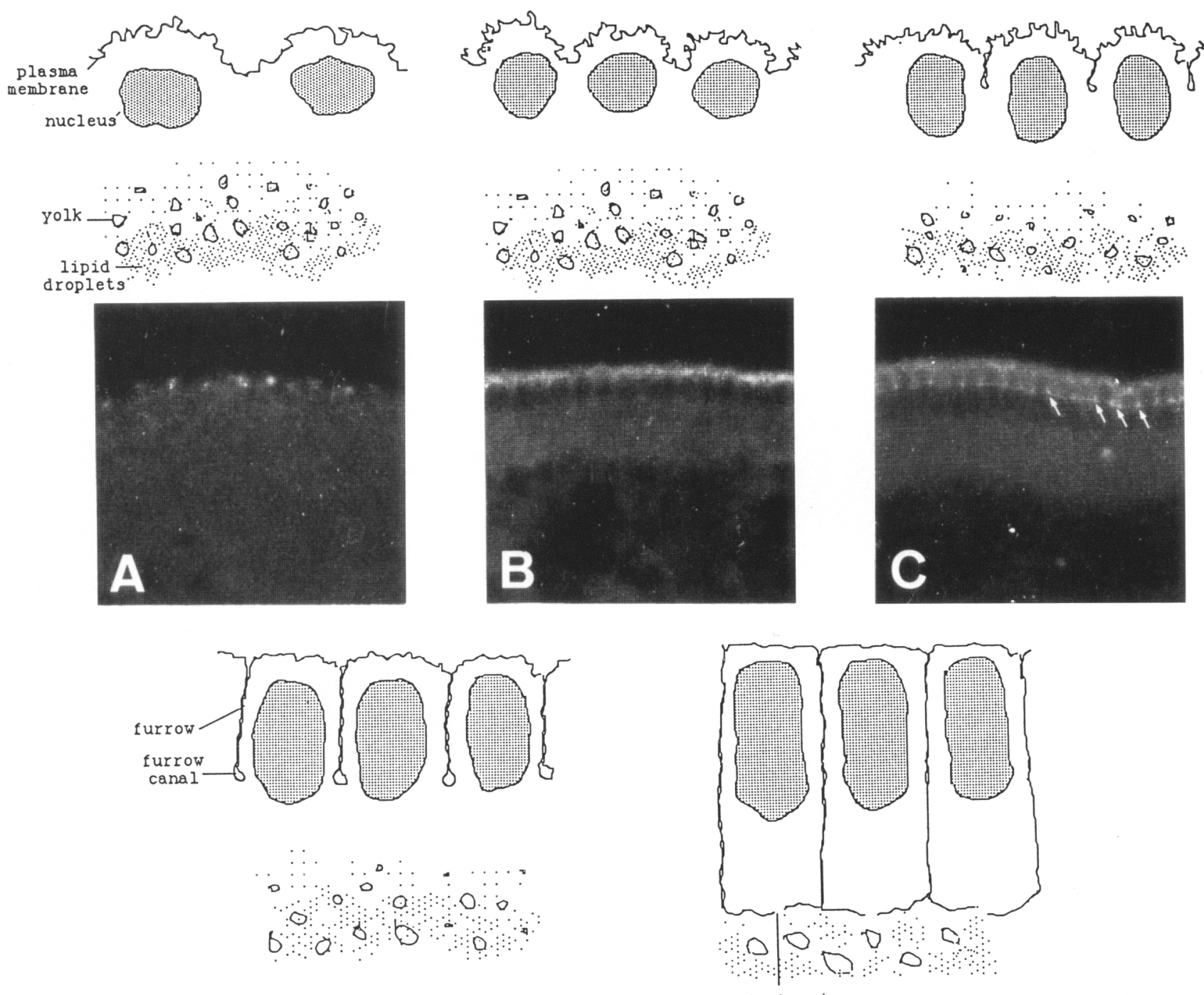

cytoplasmic
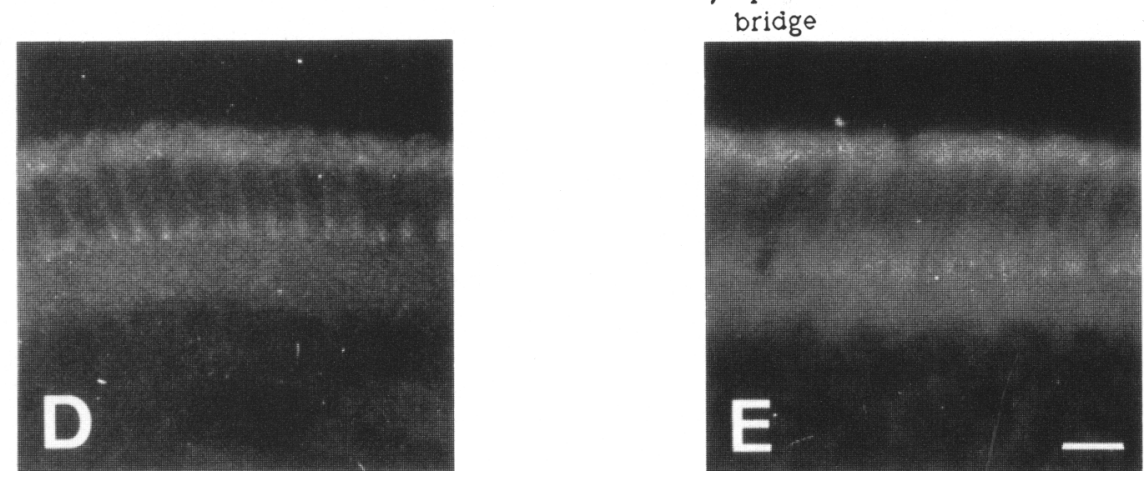

Figure 6. Localization of the sry $\alpha$ protein on cryostat sections of wild-type embryos. Immunofluorescence data are shown below a schematic representation of the cellularization process. $(A)$ The sry $\alpha$ protein is first seen in the cap region as early as nuclear cycle 13. The plasma membrane already forms numerous folds and microprojections over nuclei. $(B)$ At the beginning of the interphase of cycle 14 , the sry $\alpha$ protein is detectable close to the plasma membrane microprojections. $(C$ and $D)$ The sry $\alpha$ protein is primarily associated with the invaginating membranes during both the slow and fast phases of cellularization. During the slow phase $(C)$, the plasma membrane invaginates synchronously between adjacent nuclei. Although the egg surface is progressively flattened, microvilli are still abundant. During the fast phase $(D)$, the membrane appears to be pulled down from the remaining microvilli into the invaginating cleavage furrows. The accumulation of the sry $\alpha$ protein at the level of the furrow canal is indicated by arrows in $C$. A weak signal is also detectable in the cortical cytoplasm but not in the yolk. $(E)$ Cellularization is almost complete prior to gastrulation: Only cytoplasmic bridges remain, connecting the cytoplasm with yolk until mid-gastrulation. The sry $\alpha$ protein is then redistributed in the cytoplasm where it is presumably degraded. 
using F-actin affinity chromatography (Miller et al. 1989 ). However, the sry $\alpha$ protein does not correspond to any of these most abundant proteins identified by Miller et al. (1989) in the F-actin column eluates, based on Western blot analysis with anti-sry $\alpha$ polyclonal antibodies (C. Field and B. Alberts, pers. comm.).

An abnormal distribution of F-actin has been also described in nullo-X embryos (Wieschaus and Sweeton 1988), which is associated with a deficiency uncovering the $6 \mathrm{~F} 1-2$ region. Local disruptions of the F-actin array are also part of a more complex phenotype observed in embryos homozygous for deficiencies uncovering the 100B4-C2 region (Merrill et al. 1988). This suggests that the sry $\alpha$ gene and specific genes of the $6 \mathrm{~F} 1-2$ and $100 \mathrm{~B} 4-\mathrm{C} 2$ regions act in the same cellular process during transition between the syncytial and cellular blastoderm stages. Although phenotypically similar, these genes probably do not encode homologous proteins, because low-stringency Southern blot analysis of D. melanogaster genomic DNA failed to reveal sequences homologous to the sry a gene (data not shown).

Germinal cells bud off from the posterior pole at cycle 9 , whereas somatic nuclei are cellularized at cycle 14 . Pole cells and somatic blastoderm cells are formed under separate genetic control (Rice and Garen 1975; Merrill et al. 1988; Wieschaus and Sweeton 1988). Pole cells normally form in homozygous $D f(3 R) X 3 F$ embryos, thereby showing that the sry $\alpha$ protein is not required for polecell budding. This conclusion is supported by the temporal accumulation of the sry $\alpha$ protein, which is not detectable until mitotic cycle 12.

To our knowledge, sry $\alpha$ is the first gene to be identified that is specifically required for the cellularization of the Drosophila embryo. In contrast to ubiquitous cytoskeletal components, the sry $\alpha$ protein is specifically accumulated at the blastoderm stage. Immunodetection of the sry $\alpha$ protein thus parallels the accumulation of sry $\alpha$ transcripts as seen by in situ hybridization. sry $\alpha$ transcripts are first detectable over nuclei in syncytial blastoderm embryo at nuclear cycle 11 , transiently accumulate in all somatic cells at the interphase of cycle 14, and are no longer detectable during germ-band elongation (Schweisguth et al. 1989). The temporal restriction of sry $\alpha$ protein accumulation is thus achieved through a strict blastoderm-specific promoter (Schweisguth et al. 1989) and by the high instability of both the sry $\alpha$ mRNA and protein. This study provides a remarkable example of developmental control of cell architecture by a short-lived protein, whose transient accumulation is tightly regulated at the transcriptional level.

\section{Material and methods}

Drosophila stocks

The Oregon $\mathbf{R}$ stock of wild-type flies was used for immunocytochemistry. The $D f(3 R) X 3 F$ stock was obtained from $D r$. K. Kongsuwan. The $r y^{506}$ strain used in the transformation experiments was obtained from Dr. W. Bender. Balancers $\mathrm{CyO}$ ^TM6 $U b x / a p^{X a}$ and $C y O^{\wedge} T M 3 S b S e r y^{k} / a p^{X a}$ were obtained from
Dr. J. Merriam and Dr. J. Deutsch and were used to construct strains $\mathrm{S} 2$ and $\mathrm{S} \alpha 1$.

\section{P-element rescue}

The strain S2 was directly established from transformant line CHs829 (Kongsuwan et al. 1985), which carries a P [Jan/sry, ry $\left.{ }^{+}\right]$ element (see Table 1) on the second chromosome. The P[sry $\alpha$, $\left.\mathrm{ry}^{+}\right]$element was obtained by subcloning a $3-\mathrm{kb}$ XhoI-DraI DNA segment, which contains the sry a gene under its own control elements (Schweisguth et al. 1989), into the pDM 23 P-element vector (Mismer and Rubin 1987) opened by XbaI, filled in by Klenow enzyme, and subsequently digested by Sall. Handling of DNA followed standard protocols. P-element-mediated transformation was carried out according to Rubin and Spradling (1982), by use of $\mathrm{P} \pi 25.7 \mathrm{wc}$ as the helper (Karess and Rubin 1984). Appropriate crosses of transformed flies carrying a $\mathrm{P}\left[\right.$ sry $\left.\alpha, \mathrm{ry}^{+}\right]$element on the $\mathrm{X}$ chromosome with balancer stocks and the $D f(3 R) X 3 F$ line gave rise to the strain $S \alpha 1 . S \alpha 1$ is heterozygous for $D f(3 R) X 3 F$ and homozygous for $\mathrm{P}\left[\right.$ sry $\left.\alpha, \mathrm{ry}^{+}\right]$ Strains S2 and Sol were shown by genomic Southern blot analysis to contain the reintroduced P-element, and to have retained an embryonic lethal locus on the third chromosome. Cellular blastoderm embryos were analyzed by staining F-actin and nuclei, and their phenotypes were scored under the microscope.

\section{Staining of F-actin and DNA}

Staining was performed as described by Wieschaus and Sweeton (1988) except that glutaraldehyde was replaced by $7 \%$ formaldehyde by using fluorescently labeled (TRITC or FITC) phalloidin (Molecular Probe), diluted $1: 150$. Nuclei were stained with DAPI (Sigma). The stained embryos were examined and photographed with a Zeiss microscope equipped with epifluorescence at $25 \times, 40 \times$, and $100 \times$.

\section{Production and purification of anti-sry $\alpha$ antibodies}

Two sry $\alpha$ polypeptides, SX (37 kD) and SB (14 kD), consisting of $36-$ and $13-\mathrm{kD}$ sry $\alpha$ fragments fused to a 10 -amino-acid phage peptide, were produced in E. coli, by use of the T7 expression system (Rosenberg et al. 1987). Neither the $23-\mathrm{kD}$ amino-terminal fragment nor the full-length protein were accumulated in E. coli. The XmnI-XmnI and BamHI-BamHI DNA fragments, coding for sry $\alpha$ amino acids 229-530 (SX) and 265-370 (SB), respectively, were subcloned in-frame in the T7 expression vectors pET3 (Rosenberg et al. 1987). The resulting plasmids were introduced into the $E$. coli strain K38 pGP 1.2 (Tabor and Richardson 1985).

Bacteria were grown in L-broth supplemented with $50 \mu \mathrm{g} / \mathrm{ml}$ ampicillin, $70 \mu \mathrm{g} / \mathrm{ml}$ kanamycin, and $0.5 \mathrm{~mm}$ IPTG at $30^{\circ} \mathrm{C}$ to an $\mathrm{OD}_{600}$ of $\sim 0.8$. Synthesis of $\mathrm{T} 7$ polymerase was induced after bacteria had been washed and resuspended in L-broth prewarmed at $42^{\circ} \mathrm{C}$. Rifampicin $(150 \mu \mathrm{g} / \mathrm{ml})$ was added $20 \mathrm{~min}$ later. After a 45 -min-long heat shock, bacteria were allowed to grow for $90 \mathrm{~min}$ at $30^{\circ} \mathrm{C}$. A relatively weak polypeptide synthesis was obtained upon induction. After centrifugation and resuspension in $50 \mathrm{mM}$ Tris ( $\mathrm{pH} 7.5$ ), $150 \mathrm{mM} \mathrm{NaCl}$, and $1 \mathrm{mM}$ PMSF, bacteria from a 10-liter induced culture were sonicated $(3 \times 30 \mathrm{sec}$, with $50 \%$ duty cycle, output 6 , Vibra cell, Sonics and Materials) at $4^{\circ} \mathrm{C}$. The lysate was centrifuged twice (rotor Sorvall $\mathrm{HB} 4,4^{\circ} \mathrm{C}$ ) at $4000 \mathrm{rpm}$ and $9000 \mathrm{rpm}$. A large fraction of enriched polypeptides was recovered in the second pellet and was subjected further to preparative SDS-PAGE. The gel slice 
containing the SB polypeptide was visualized by incubating the gel in $0.25 \mathrm{M} \mathrm{KCl}$ at $4^{\circ} \mathrm{C}$, excised, and electroeluted. After extensive dialysis against PBS, the purified SB antigen was mixed with one volume of complete Freund's adjuvant (incomplete for booster injections). Alternatively, both SB and SX polypeptides were electroblotted onto a nitrocellulose filter. After visualization of proteins with Ponceau Red, nitrocellulose strips were excised and sonicated in PBS until a fine powder was recovered $15 \times 30 \mathrm{sec}$, pulsed at $4^{\circ} \mathrm{C}$, with $50 \%$ duty cycle, output 6 , Vibra cell, Sonics and Materials). Four rabbits were injected at multiple subcutaneous sites and boosted every 3 weeks (repeated five times) until a high titer was reached.

A $\beta$-galactosidase-sry $\alpha$ fusion protein, consisting of a carboxy-terminal $34-\mathrm{kD}$ fragment (amino acids $247-530$ ) fused to the $E$. coli $\beta$-galactosidase, was used for the purification of the antibody. The corresponding BglII-HindIII sry $\alpha$ DNA fragment was inserted in-frame in the pUR 290 expression vector (Rüther and Müller-Hill 1983), opened by BamHI and HindIII. Synthesis of the fusion protein under control of the lac promoter was induced for $2 \mathrm{hr}$ with $1 \mathrm{mM}$ IPTG at room temperature to minimize aggregation of the induced protein. Bacteria were sonicated and centrifuged as above. The fusion protein was affinitypurified from the supernatant on an APTG agarose column (Sigma) and used to prepare an affinity column (Affi-Gel 10, Bio-Rad), according to the manufacturer's protocol. Specific anti-sry $\alpha$ antibodies from the IgG fraction of the DEAE-purified sera were affinity-purified, as described by Caroll and Scott (1985). Antibodies raised against bacterial antigens were absorbed on an affinity column prepared with $E$. coli extracts. The specificity of the purified anti-sry $\alpha$ antibodies was determined first on immunoblots of bacterial extracts. Each serum raised against one antigen specifically recognized both SX and SB polypeptides. All sera gave qualitatively similar results on embryos. Western blot analysis was carried out with immunopurified antibodies from a serum raised against the electroeluted SB antigen, and immunostaining and immunofluorescence data were obtained by using antibodies purified from a serum raised against the SX protein bound to a nitrocellulose support.

\section{Western blot}

Embryonic extracts were prepared according to Bastiani et al. (1987). The proteins present in the postmitochondrial supernatant partition in a $2: 3$ ratio after centrifugation at $100,000 \mathrm{~g}$ between the pellet (12 $\mathrm{mg}$ of total protein) and the supernatant (18 $\mathrm{mg}$ of total protein) that constitute the crude membrane and the cytosolic fractions, respectively. In vitro transcription and translation were performed according to the manufacturers' indications (Stratagene and Promega, respectively). Proteins separated on $10 \%$ SDS-PAGE were electroblotted onto nitrocellulose filters. Incubation with the first antibody, anti-sry $\alpha$ at a $1: 500$ dilution, was overnight at room temperature. Subsequent steps were carried out as indicated by the manufacturer of the blotting detection kit (Amersham), except the secondary antibody was diluted $1: 20,000$ instead of $1: 500$.

\section{Whole-mount staining}

Embryos were incubated overnight at room temperature with anti-sry $\alpha$ antibodies, diluted $1: 200$. Whole-mount preparations of embryos were stained by using the Vectastain ABCperoxidase "Elite" system (Vector Laboratories), according to Macdonald and Struhl (1986). Stained embryos were mounted in Epon 812. Photographs were taken with a Zeiss microscope equipped with Nomarski optics.

\section{Immunofluorescence}

Embryos of the appropriate stage were dechorionated with commercial bleach, fixed at the interphase of heptane and $4 \%$ paraformaldehyde in $10 \mathrm{mM} \mathrm{KPO}_{4}(\mathrm{pH} 6.8), 45 \mathrm{~mm} \mathrm{KCl}, 15 \mathrm{~mm}$ $\mathrm{NaCl}$, and $15 \mathrm{mM} \mathrm{MgCl}$, and devitellinized with vigorous shaking in methanol at room temperature. After progressive rehydration in PBS, embryos were embedded in Tissue-Tek OCT (Miles). Frozen sections of $\sim 5 \mu \mathrm{m}$ were air-dried for $\mathrm{l} \mathrm{hr}$, rehydrated for 10 min in PBS, incubated first in PBS (pH 7.5), 1\% BSA (grade V), and $0.1 \%$ Tween 20 and then overnight with affinity-purified antibodies at a $1: 100$ dilution in the same buffer containing $1 \%$ goat serum. The TRITC-labeled goat antirabbit second antibody (Cappel) was incubated $2 \mathrm{hr}$. All steps were carried out at room temperature. Double immunofluorescence labeling was carried out on whole embryos prepared according to Karr and Alberts (1986), and incubated overnight at $4^{\circ} \mathrm{C}$ using rabbit anti-spectrin polyclonal antibodies (serum 905: Pesacreta et al. 1989) and monoclonal anti- $\alpha$-tubulin (Amersham), both diluted $1: 1000$. Secondary antibodies, FITC-labeled goat anti-mouse antibodies (KPL) and TRITC-labeled goat anti-rabbit antibodies (Cappel), were applied for $1 \mathrm{hr}$ at room temperature. Sections and whole-mount embryos were mounted in $1: 1 \mathrm{PBS} / g$ lycerol and photographed with a Zeiss photomicroscope equipped with epifluorescence at $40 \times, 63 \times$, and $100 \times$, using Kodak Tri-pan film (400 ASA).

\section{Acknowledgments}

We thank E. Wieschaus for communicating results prior to publication, R. Dubreuil and D. Branton for the gift of antispectrin antibodies, S. Noselli for injections, and J. Deutsch and J.-M. Camadro for helpful experimental advice. We are grateful to F. Amalric, J. Cartaud, J. Deutsch, B. Maro, A. Nicholson, E. Schejter, L. Simpson and, particularly, E. Wieschaus for critical reading of the manuscript. Thanks also go to $R$. Schwartzman for photographic work and stimulating discussions.

\section{References}

Bastiani, M.J., A.H. Harrelson, P.M. Snow, and C.S. Goodman. 1987. Expression of fasciclin I and II glycoproteins on subsets of axons pathways during neuronal development in the grasshopper. Cell 48: 745-755.

Bordier, C. 1981. Phase separation of integral membrane proteins in Triton X-114. J. Biol. Chem. 256: 1604-1607.

Campos-Ortega, J.A. and V. Hartenstein. 1985. The embryonic development of Drosophila melanogaster. Springer-Verlag, Berlin/Heidelberg/New York/Tokyo.

Caroll, S.B. and M.P. Scott. 1985. Localization of the fushi tarazu protein during Drosophila embryogenesis. Cell 43: 47-57.

Driever, W. and C. Nüsslein-Volhard. 1988. A gradient of bicoid protein in Drosophila embryos. Cell 54: 83-93.

Edgar, B.A., G.M. Odell, and G. Schubiger. 1987. Cytoarchitecture and the patterning of fushi tarazu expression in the Drosophila blastoderm. Genes Dev. 1: 1226-1237.

Foe, V.E. and B.M. Alberts. 1983. Studies of nuclear and cytoplasmic events during the five mitotic cycles that precede gastrulation in Drosophila embryogenesis. I. Cell Sci. 61: $31-70$.

Fullilove, S.L. and A.G. Jacobson. 1971. Nuclear elongation and cytokinesis in Drosophila montana. Dev. Biol. 26: 560577.

Garcia-Bellido, A., J. Moscoso del Prado, and J. Botas. 1983. The 
effects of aneuploidy on embryonic development in Drosophila melanogaster. Mol. Gen. Genet. 192: 253-263.

Ingham, P.W. 1988. The molecular genetics of embryonic pattern formation in Drosophila. Nature 335: 25-33.

Karess, R.E. and G. Rubin. 1984. Analysis of P transposable element functions in Drosophila. Cell 38: 135-146.

Karr, T.L. and B.M. Alberts. 1986. Organization of the cytoskeleton in early Drosophila embryos. I. Cell Biol. 102: 1494-1509.

Kongsuwan, K., Y. Quiang, A. Vincent, M.C. Frisardi, M. Rosbash, J.A. Lengyel, and J. Merriam. 1985. A Drosophila minute gene encodes a ribosomal protein. Nature 317: 555558.

Macdonald, P.M. and G. Struhl. 1986. A molecular gradient in early Drosophila embryos and its role in specifying the body pattern. Nature 324: 537-545.

Merrill, P.T., D. Sweeton, and E. Wieschaus. 1988. Requirements for autosomal gene activity during precellular stages of Drosophila melanogaster. Development 104: 495-510.

Miller, K.G., C.M. Field, and B.M. Alberts. 1989. Actin-binding proteins from Drosophila embryos: A complex network of interacting proteins detected by F-actin affinity chromatography. I. Cell Biol. 109: 2963-2975.

Mismer, D. and G.M. Rubin. 1987. Analysis of the promoter of the ninaE opsin gene in Drosophila melanogaster. Genetics 116: $565-578$.

Pesacreta, T.C., T.J. Byers, R. Dubreuil, D.P. Kiehart, and D. Branton. 1989. Drosophila spectrin: The membrane skeleton during embryogenesis. I. Cell Biol. 108: 1697-1709.

Piovant, M. and P. Lena. 1988. Membrane glycoproteins immunologically related to the human insulin receptor are associated with presumptive neuronal territories and developing neurones in Drosophila melanogaster. Development 103: $145-156$

Rice, T.B. and A. Garen. 1975. Localized defects of blastoderm formation in maternal effect mutants of Drosophila. Dev. Biol. 43: 277-286.

Rosenberg, A.H., B.N. Lade, D.S. Chui, S.W. Lin, J.J. Dunn, and F.W. Studier. 1987. Vectors for selective expression of cloned DNAs by T7 RNA-polymerase. Gene 56: 125-135.

Rubin, G.M. and A.C. Spradling. 1982. Genetic transformation of Drosophila with transposable element vectors. Science 218: $348-353$.

Rüther, U. and B. Müller-Hill. 1983. Easy identification of cDNA clones. EMBO I. 2: 1791-1794.

Sanders, E.J. 1975. Aspects of furrow membrane formation in the cleaving Drosophila embryo. Cell Tiss. Res. 156: 463474.

Schüpbach, T. and E. Wieschaus. 1989. Female-sterile mutations on the second chromosome of Drosophila melanogaster. I. Maternal effect mutations. Genetics 121: 101-117.

Schweisguth, F., C. Yanicostas, F. Payre, J.-A. Lepesant, and A. Vincent. 1989. Cis-regulatory elements of the Drosophila blastoderm-specific serendipity alpha gene: Ectopic activation in the embryonic PNS is promoted by the deletion of an upstream element. Dev. Biol. 136: 181-193.

Tabor, S. and C.C. Richardson. 1985. A bacteriophage T7 RNA polymerase/promoter system for controlled exclusive expression of specific genes. Proc. Natl. Acad. Sci. 82: 10741078.

Tellam, R.L., D.J. Morton, and F.M. Clarke. 1989. A common theme in the amino acid sequences of actin and many actinbinding proteins? Trends Biochem. Sci. 14: 130-133.

Turner, F.T. and A.P. Mahowald. 1976. Scanning electron microscopy of Drosophila embryogenesis. Dev. Biol. 50: $95-$ 108.
Vincent, A., H.V. Colot, and M. Rosbash. 1985. Sequence and structure of the serendipity locus of Drosophila melanogaster. A densely transcribed region including a blastodermspecific gene. J. Mol. Biol. 186: 149-166.

1986. Blastoderm-specific and read-through transcription of the sry alpha gene transformed into the Drosophila genome. Dev. Biol. 118: 480-487.

Warn, R.M. 1986. The cytoskeleton of the early Drosophila embryo. J. Cell Sci. 5: 311-328.

Warn, R.M. and R. Magrath. 1983. F-actin distribution during the cellularization of the Drosophila embryo visualized with FL-phalloidin. Exp. Cell Res. 143: 103-114.

Warn, R.M. and A. Warn. 1986. Microtubule arrays present during the syncytial and cellular blastoderm stages of the early Drosophila embryo. Exp. Cell Res. 163: 201-210.

Warn, R.M., B. Bullard, and R. Magrath. 1980. Changes in the distribution of cortical myosin during the cellularization of the Drosophila embryo. I. Embryol. Exp. Morph. 57: 167176.

Wieschaus, E. and D. Sweeton. 1988. Requirements for Xlinked zygotic gene activity during cellularization of early Drosophila embryos. Development 104: 483-494.

Yanicostas, C., A. Vincent, and J.A. Lepesant. 1989. Transcriptional and post-transcriptional regulation contributes to the sex-regulated expression of two sequence-related genes at the janus locus of Drosophila melanogaster. Mol. Cell. Biol. 9: $2526-2535$.

Zalokar, M., C. Audit, and I. Erk. 1975. Developmental defects of female-sterile mutants of Drosophila melanogaster. Dev. Biol. 47: 419-432. 


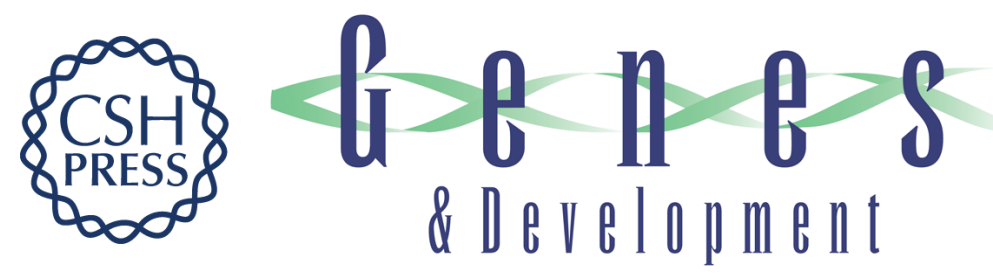

\section{The serendipity alpha gene encodes a membrane-associated protein required for the cellularization of the Drosophila embryo.}

F Schweisguth, J A Lepesant and A Vincent

Genes Dev. 1990, 4:

Access the most recent version at doi:10.1101/gad.4.6.922

References This article cites 37 articles, 14 of which can be accessed free at:

http://genesdev.cshlp.org/content/4/6/922.full.html\#ref-list-1

License

Email Alerting

Service right corner of the article or click here.

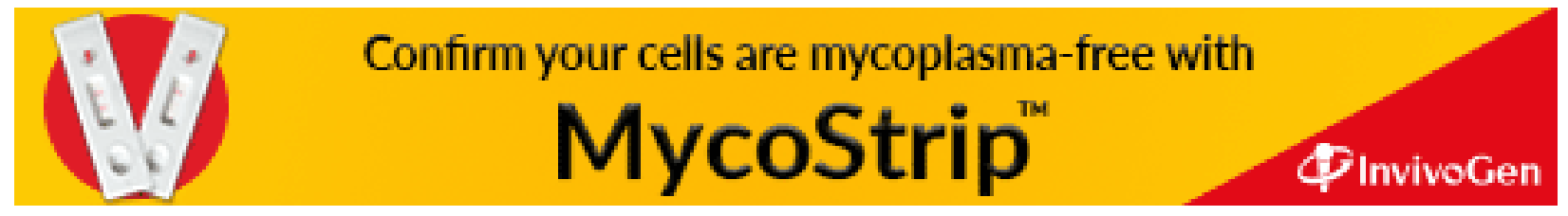

